\title{
A THEORETICAL FRAMEWORK FOR MULTI-SCALE DOCUMENTATION OF DECORATED SURFACES
}

\author{
M. Reina Ortiz ${ }^{1, *}$, A. Weigert ${ }^{1}$, A. Dhanda ${ }^{1}$, C. Yang ${ }^{2}$, K. Smith ${ }^{1}$, A. Min $^{3}$, M. Gyi ${ }^{4}, \mathrm{~S} \mathrm{Su}^{4}, \mathrm{~S} . \mathrm{Fai}^{1}$, M. Santana Quintero ${ }^{1}$ \\ ${ }^{1}$ Carleton Immersive Media Studio (CIMS), Carleton University, Ottawa, Canada - (adhanda, aweigert, sfai)@cims.carleton.ca, \\ (miquel.reinaortiz, mario.santana, kristen.smith)@cmail.carleton.ca \\ ${ }^{2}$ Guo Wen Yan Conservation Science and Technology Co., Ltd, Haidian District, Beijing, 100192 - cyang conservation@163.com \\ ${ }^{3}$ Department of Archaeology and National Museum, Bagan, Myanmar \\ ${ }^{4}$ Mandalay Technological University, Mandalay, Myanmar
}

\section{Commission II, WG II/8}

KEY WORDS: Wall Painting Conservation, Cultural Heritage Documentation, Multi-scale Documentation, GIS, HBIM

\begin{abstract}
:
Wall paintings are a unique case of decorated surfaces because of its direct relation to the supporting structure. This paper points out the importance of considering the conservation of wall paintings from its fourth-dimensionality - surface (2D), depth (3D), and time (4D) - and taking into account three different scales - surface, building, and territory. The relationship between these three scales becomes significant with a case study of three temples: Loka-hteik-pan, Myin-pya-gu, and Kubyauk-nge, in the context of Old Bagan (Myanmar), where more than 2,500 temples with valuable wall paintings exist. To that end, firstly, different documentation techniques and management methods are reviewed for each of the scales proposed; secondly, a multi-scale documentation project, mostly unexplored within the context of wall paintings, is developed using BIM and GIS. Ultimately, the case study in Old Bagan proposes a comprehensive methodology to document and manage wall paintings that belong to a large group of heritage assets considering its four-dimensionality at multiple scales, addressing the interoperability at a basic level between: (1) surface and building, (2) building and territory, and (3) surface and territory. The objective is to create data exchange among different platforms and users, generating a collaborative instrument that evolves with the participation of different specialists.
\end{abstract}

\section{INTRODUCTION}

The conservation challenges related to decorated surfaces are usually referred to the detail of its external layer. Wall paintings, as a type of decorated surfaces, pose challenges in conservation because of its intimate connection with the supporting structure (Figure 1). An effective and ethical conservation approach needs to stress the importance of threedimensional stratigraphy as well as time- the fourth-dimension of wall paintings (Cather, 1999; Cather, 2010). This paper acknowledges the importance of documentation in wall painting conservation, and following this approach posits the necessity to develop the process from three different scales-surface, building, and territory-to truly understand the decorated surface for its conservation.

The documentation project of different temples in Old Bagan (Myanmar) during the summer of 2018 was conducted by a multidisciplinary team formed by members of Carleton University, Department of Archaeology and National Museum of Bagan, and Mandalay Technological University. The scope of the project included four temples, with a particular interest in the detailed documentation of wall paintings. The project outcome raised questions such as the relationship between different scales: from one specific detail of a wall painting (surface), to a south-facing section of wall within a temple (building), to all temples with painted schemes-more than 2,500 in the area (territorial). Another question was how different territorial circumstances - for example, earthquakesaffect the site as well as individual temple and painting.

To that end, the contribution of this paper is to review current practices in each of the scales-surface, building, and territory - and propose a theoretical framework for the multi- scale documentation of wall paintings. This approach is exemplified with the development of a case study in Old Bagan that focuses on three temples: Loka-hteik-pan, Myin-pya-gu, and Kubyauk-nge, and their interior wall paintings.

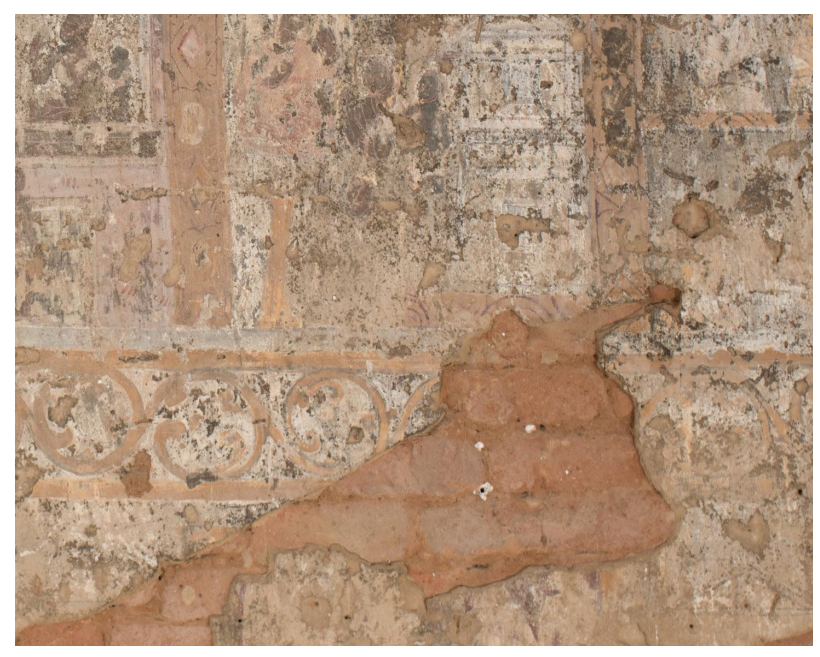

Figure 1. The stratigraphy of wall paintings in Myinpya-gu — a temple in Old Bagan, Myanmar.

\subsection{Documentation of Wall Paintings}

In the process of wall painting conservation, documentation provides a fundamental basis for decision-making (Cather and Schmid, 2000). The major purposes of heritage documentation include academic research, conservation, site management, and dissemination. Specific purposes for wall paintings are subject 
to different projects. Generally, the intention of wall painting documentation includes art historical studies, technical studies such as original technology, workshop practice, and archaeological findings. The recording of the condition involves visual glossary of phenomena and graphic documentation of their distribution and characteristics (Martin de Fonjaudran et al., 2011). In terms of conservation, documentation facilitates diagnostic investigations to address conservation issues. The intervention process also requires documentation, especially in its implementation and assessment. Moreover, different kinds of monitoring could be significantly enhanced once digitally integrated with the help of documentation. For site management, aspects such as visitor impact, infrastructure, and safety measures are documented and evaluated under the same scope (Agnew and Demas, 2013; Wong et al., 2012). The dissemination to targeted audiences is tailored to suit various purposes, but the fundamental data source comes from the documentation.

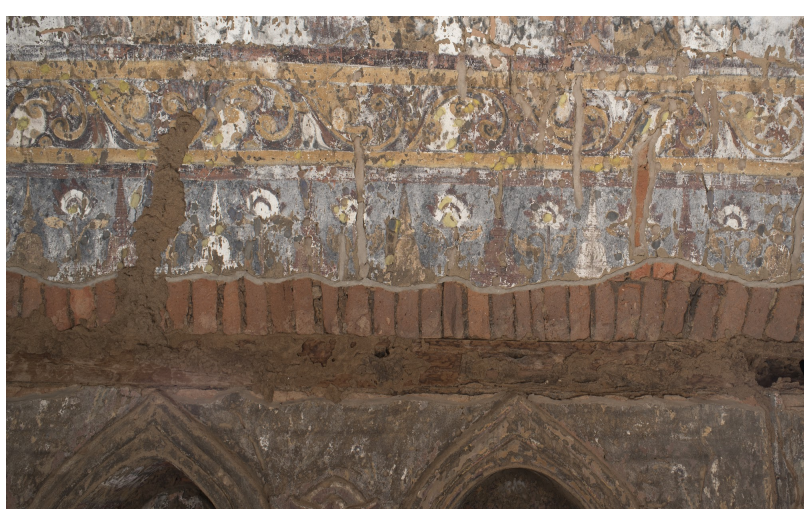

Figure 2. Interior wall painting scheme of Myin-pya-gu.

Requirements for wall painting documentation can be categorized according to the level of detail, accuracy, and scope (Cather, 2000). A site-scaled inventory provides the context, such as the geographical and historical information, usage, iconography and decorating motif, values, and significance. An accurate and complete imagery inventory is vital for art historians and dissemination purposes. Detailed photography for conservation involves the recording of condition phenomena, monitoring of specific area/issue, or preparation for sampling (Figure 2). For diagnostic investigations, documentation may require graphic facilitation in non-invasive analysis/characterization, such as portable-microscopy, elemental analysis, multispectral imaging, and infrared thermography. Intangible aspects of wall paintings, such as the demonstration of traditional techniques, cultural events and rituals, and oral history, should also be incorporated into the documentation procedure. In all, it is the integration of data sources that chronically challenge wall painting documentation.

\section{RELATED WORKS}

At the surface scale, the documentation of wall paintings utilizes a variety of imaging techniques. For example, visible and ultraviolet photography, infrared reflectography, together with color measurements and representation, were used for the documentation of Byzantine wall painting schemes (Daniilia et al., 2000). Reflectance Transformation Imaging (RTI) is applied to enhance the readability and documentation of some historical graffiti-covered wall paintings (Cosentino and Stout, 2015). Other imaging techniques include gamma-corrected images and photogrammetry (Andreoli, 2014). In some cases, the image processing is completed with the illustration of conservationrelevant aspects using CAD software (Abate, et al., 2016).

At the building scale, the use of HBIM is becoming frequent, but research has been rarely undertaken to explore its application in the conservation of wall paintings. In the field of tiles and mosaics conservation, some studies have been relatively developed. One example is the use of $3 \mathrm{D}$ modeling to generate an efficient and accurate representation of flooring and wall tiling (Nieto et al., 2016). This proposal acknowledges the qualities of BIM for processes such as the integration of images in the model using photogrammetric orthographic images, the identification and cataloging of irregular pieces, and information management. In the apartment of Troia of Giulio Romano, BIM tools helped overcome limitations of twodimensional presentation of the irregular walls (Adami, et al., 2017).

At the territorial scale, survey and inventories specifically regarding wall paintings are scarce; however, there are outstanding site surveys such as the Theban Mapping Project, which incorporates tombs, temples and monuments geographically scattered in the Luxor region (TMP, 2004). Another example of a comprehensive survey was conservationrelated aspects in the Valley of the Queens, Luxor conducted by the Getty Conservation Institute (Demas and Agnew, 2012).

Nevertheless, these studies do not address the composition, stratigraphy, or physical history of the wall painting, and the integration of factors affecting its conservation is insufficient. Therefore, in order to accomplish satisfactory documentation of the wall painting, further research is required in the proposed multi-scale approach.

\section{MULTI-SCALE DOCUMENTATION APPROACH}

This paper posits the necessity for the integration of different data sources developed at different scales. This is relevant in wall painting conservation because it depends as much on a detailed knowledge of its material composition as on an understanding of its spatial and historical context. Therefore, different documentation techniques need to be integrated into a comprehensive system, to allow the navigation amongst different scales.

Surface-scale documentation requires techniques such as closerange photogrammetry, photometric-stereo, raking light imaging, and hand-held laser scanning. Building-scale documentation requires techniques such as surveying, terrestrial laser scanning, and terrestrial photogrammetry. This also applies to individual wall painting schemes and large-scale condition phenomena. Territory-scale documentation requires techniques such as Light Detection and Ranging (LiDAR), aerial photogrammetry, and aerial imaging. The goal of each documentation scale is different but related; from the generation of an inventory at the territorial scale, to an understanding of the wall painting within its context in the structure, to the composition, condition, and topography of a specific area on the painted surface.

\section{CASE STUDY: OLD BAGAN}

The case study developed for this paper is located in Old Bagan (Myanmar) (Figure 3) and draws on the 2018 documentation workshop that focused on training local students and professionals as well as documenting temples with particular attention to wall paintings. 
The starting point for the documentation work was the inventory initiated by Pierre Pichard in 1982 and finished in 1999. In his survey, he listed 2834 monuments in Bagan and gathered graphic documentation, pictures, and other relevant data. For each monument, the inventory contains: inventory number, name, broad location, coordinates, short description, plan of main stories, and significant photographs. Pichard surveyed the present condition and the decoration (exterior and interior) of each asset (Pichard, 1992). During the workshop, several inventories generated by Pichard were made again to evaluate its change and the effects of the earthquake in August 2016.

The goal of this case study is to review all the techniques used to document wall paintings during the workshop and propose a comprehensive approach that considers its fourdimensionality - surface, depth, and time - at its three scales of intervention - surface, building, and territory.

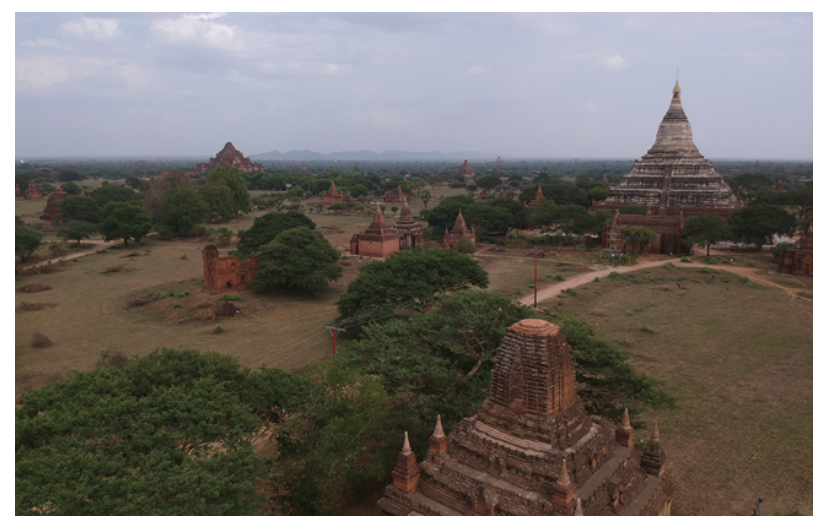

Figure 3. Aerial photography of Old Bagan (Myanmar).

\section{SURFACE SCALE}

\subsection{Surface Scale Documentation}

The surface scale documentation of decorated surfaces can be done using three categories of techniques: passive sensing, active sensing, and traditional techniques (Table 1). Raking light provides a good textural presentation. It is usually used in condition monitoring combined with images under incident light. On the macro to the micro level, a portable microscope reveals detailed information under magnification. Remondino et al., 2011 discussed many of the passive and active techniques.

\subsection{Surface Management}

The wide variety of data types in surface scale documentationphotographs, point clouds, 3D meshes, text documents and drawings - makes it hard to have one platform where all data can be integrated and used for decorated surfaces. The difficulty integrating $2 \mathrm{D}$ and $3 \mathrm{D}$ data sets can be somewhat mitigated with a carefully planned and hardware-integrated approach during acquisition and data processing (Fontana et al., 2003). However, on the software end, no widely accepted interface is currently used to manage and link the data all together. Schroer et al., (2017) introduced the Digital Lab Notebook, a way of keeping acquisition information linked to the acquisition data. Pamart et al., (2017) and Rahrig et al., (2018) used layered orthographic projections to layer 2D and 3D data. Remondino et al., (2011) used a GIS to integrate multispectral photography with orthophotos and DEMs of a painting. Nocerino et al., (2018) created a web viewer that lets the user cycle between the VIS and UVL-textured model of a painted vase. Pamart et al., (2019) developed a framework for integrating 2D, 3D, and RTI data sets.

\begin{tabular}{|c|c|c|}
\hline $\begin{array}{c}\text { Passive Sensing } \\
\text { Techniques }\end{array}$ & $\begin{array}{c}\text { Active Sensing } \\
\text { Techniques }\end{array}$ & $\begin{array}{c}\text { Traditional / } \\
\text { Physical } \\
\text { Techniques }\end{array}$ \\
\hline $\begin{array}{c}\text { Photography } \\
\text { (Colour, } \\
\text { multispectral, } \\
\text { raking light) }\end{array}$ & $\begin{array}{c}\text { Triangulation- } \\
\text { based scanning }\end{array}$ & $\begin{array}{c}\text { Hand } \\
\text { measurements / } \\
\text { Drawings }\end{array}$ \\
\hline $\begin{array}{c}\text { Close range } \\
\text { photogrammetry }\end{array}$ & $\begin{array}{c}\text { Structured light } \\
\text { scanning }\end{array}$ & Casting \\
\hline $\begin{array}{c}\text { RTI / Photometric } \\
\text { stereo }\end{array}$ & & $\begin{array}{c}\text { Non-invasive and } \\
\text { invasive sampling } \\
\& \text { analysis }\end{array}$ \\
\hline
\end{tabular}

Table 1. A summary of surface scale documentation techniques.

\subsection{Case Study: Bagan}

The decorated surfaces of the four temples were documented using VIS photography (Figure 4), close range photogrammetry (Figure 5), and reflectance transformation imaging (RTI). Photogrammetry was used to capture surface details over a wider area, while RTI was used to capture more detailed surface information in a few specific areas of interest.

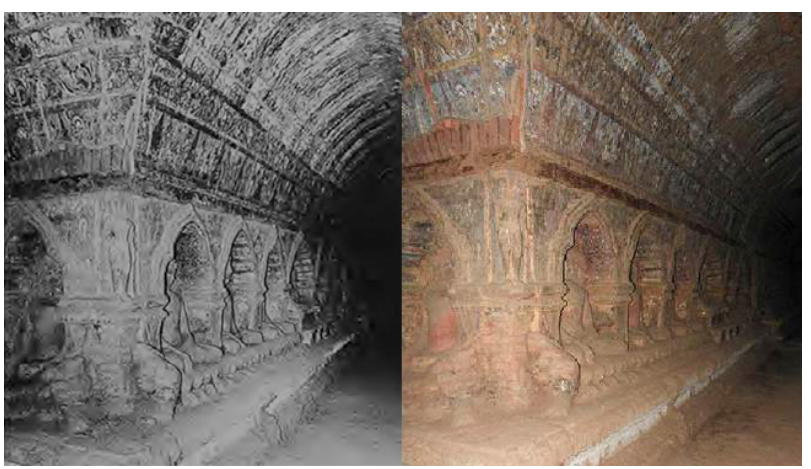

Figure 4. Photographic comparison of the same corridor in Myin-pya-gu (1982-2018) (Pichard,1992).

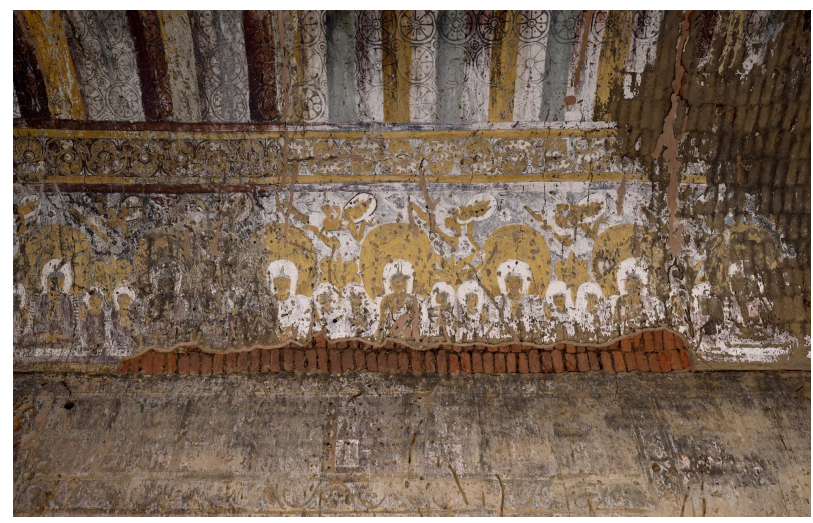

Figure 5. Render of interior wall painting photogrammetry in Mying-pya-gu. 


\section{BUILDING SCALE}

\subsection{Building Scale Documentation}

Measured and Drawn (Andrews et al., 2009)—a long-standing reference-describes documentation techniques of heritage places at the building scale. It aims to show that a metric survey can be a reliable tool to allow for the collaboration of heritage professionals. There are two groupings of techniques within a metric survey: indirect and direct, which is slightly different from active and passive sensing techniques. Direct techniques include using photogrammetry (terrestrial and UAV) and laser scanning to take measurements freely, whereas indirect techniques include using a Total Station Theodolite (TST), Global Positioning System (GPS) or hand measures to make specific measurements (Andrews et al., 2009).

\subsection{Building Management}

Traditionally, building representations are in 2D Line drawing formats (Figure 6). The practice of measuring and drawing existing buildings has matured with computer-aided design (CAD) technologies. Information from hand measurements, total station surveys, rectified photography, photogrammetry, and laser scanning measurements represent digital and analog data sets, which can be integrated into one drawing package. Within a 2D CAD software, the information can then be layered, revealing information separately. This is important when dealing with multiple levels of detail and the additional dimension of time; for example, drawing architectural elements whilst recording damage, decay and/or deterioration for the condition assessment.

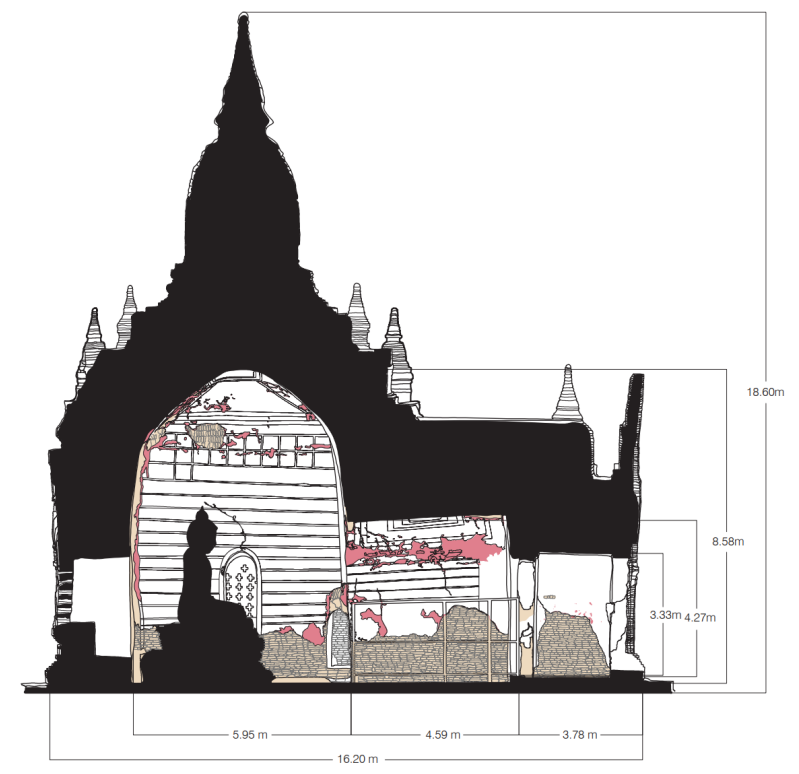

Figure 6. Condition assessment of Loka Hteik Pan (Mezzino et al,. 2017).

The early research of Fai et al. (2011) explores how BIM can be extended to documentation and conservation of architectural heritage. They gathered construction drawings, laser scan data, topographic drawings, historical surveys, and photographs. The BIM phasing tools allowed for the addition of the fourth dimension of time; multiple versions of a building can be represented as stages of its lifetime. They expanded their work by creating an online BIM database: Cultural Diversity and Material Imagination in Canadian Architecture (CDMICA).
Information management is still mostly document-based; current research in historic building information models (HBIM) still aims to integrate the multiple data sets (Remondino and Stylianidis, 2016). BIM has yet to be used as a tool for integrating wall painting information.

Measurements, drawings, and BIMs integrate datasets primarily for the architecture, engineering, and construction industry are not always in a form for public consumption. Other techniques like virtual tours and virtual reality (VR) applications have the ability to integrate and disseminate cultural heritage - specially decorated surfaces - at the building scale.

\subsection{Case Study: Bagan}

Documentation at the building scale was the focus of the workshop in Bagan. Laser scanning and photogrammetry were captured in a registered local coordinate system created during the survey. Photographic and panoramic data was also gathered to document character-defining elements, conditions, interior and exterior views. The Loka Hteik Pan Temple was unique because it was documented twice: once in the 2016 workshop and once in the 2018 workshop. From the 2016 documentation data, a BIM was created of Loka Hteik Pan (Figure 7).

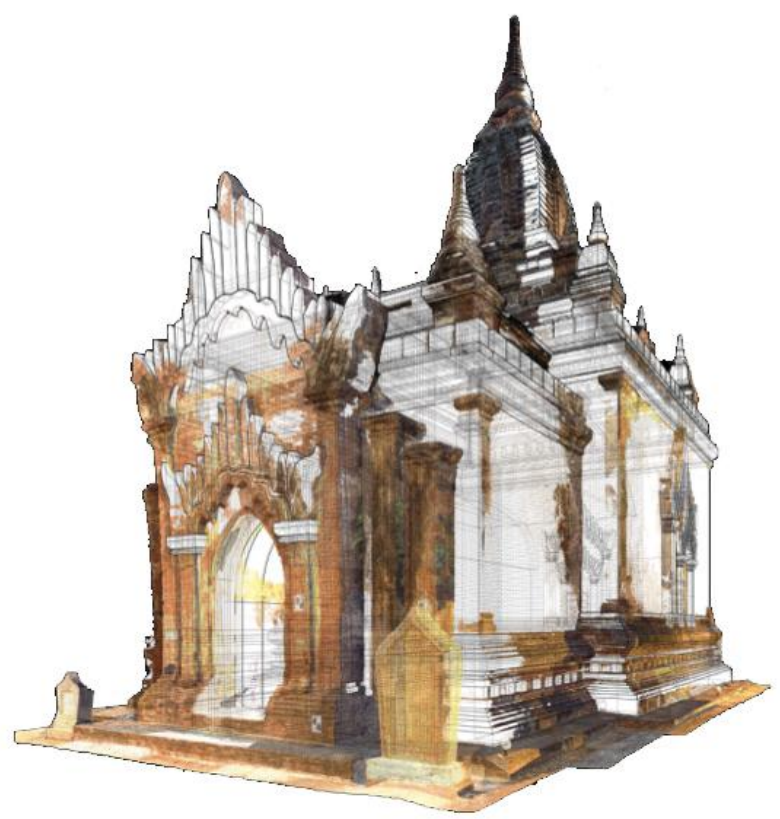

Figure 7. BIM of Loka Hteik Pan (Mezzino et al., 2017).

\section{TERRITORIAL SCALE}

\subsection{Territorial Scale Documentation}

At the territorial scale, documentation strategies focus on generating a geospatially referenced inventory of wall paintings. This inventory situates wall painting positions and attributes within a 3D cartographic model of the site's urban context. To generate this model, both active and passive recording strategies 
may be employed. LiDAR, an active sensing technology, uses UAV-mounted lasers to capture spatial data over a large region. The output is typically a sparse $3 \mathrm{D}$ point cloud, which may be selectively supplemented with data gathered terrestrially. Aerial photogrammetry - a passive sensing technology - uses UAVmounted cameras or satellites to capture 2D surface imagery. This imagery may later be translated into a triangulated surface, featuring the original groundplane's true color spectrum. Finally, both of these techniques can be combined with traditional land surveys and correlated to historical maps.

\subsection{Territorial Management}

The use of GIS (Geographic Information Systems) begins with land planning and environmental monitoring, transitioning after to management of archaeological investigations and finally in cultural heritage asset management (Madden, 2009). At present, a standardized methodology for documenting cultural heritage at a territorial scale exists primarily for historic buildings rather than wall paintings (Barton et al., 2017). In other fields, such as urban planning, territorial datasets are compiled in geospatial software such as ArcGIS PRO, QGIS, or ARCHES. Terrain and building envelopes may then be generated from raw LiDAR or photogrammetric data. Subsequently, 2D or 3D geometry can be created to symbolize the position and configuration of wall paintings at an urban scale. Collectively, this information builds an inventory correlating spatial geometry to non-spatial wall painting attributes. Each layer remains discrete in the inventory, allowing regular updates of information such as wall painting conditions and recording histories.

\subsection{Case Study: Bagan}

The case study of Bagan has the objective to generate an inventory of documented wall paintings considering the fourdimensionality proposed by Cather (Cather, 2010). To that end, a GIS is generated with ESRI ArcGIS PRO incorporating information of different temples and wall paintings documented. Additional territorial visualizations may be produced using software such as Autodesk Infraworks and ESRI CityEngine. The primary layers of information generated for the GIS include:

1. The volumetric geometry of the documented temples at LOD (3) (Figure 8).

2. The wall painting geometry and position within the building-imparted with numeric and/or textual attributes describing critical traits of each element (Type of painting, type of support, year of realization, year of restorations, etc.) (Figure 9).

Secondary layers of information at the territorial data are also considered:

1. Topography of territory.

2. Urban settlements.

3. Social data (population, artesans, etc.).

4. Natural causes (earthquakes) (Figure 10).

ArcGIS PRO allows a quick view of the territory and the different assets related to wall paintings. In order to achieve the 4D aspect, other relevant information is added, such as the survey developed by Pierre Pichard during 1982-1999. Additionally, the GIS aims to incorporate all the surveys and documentation techniques developed to date and future ones.

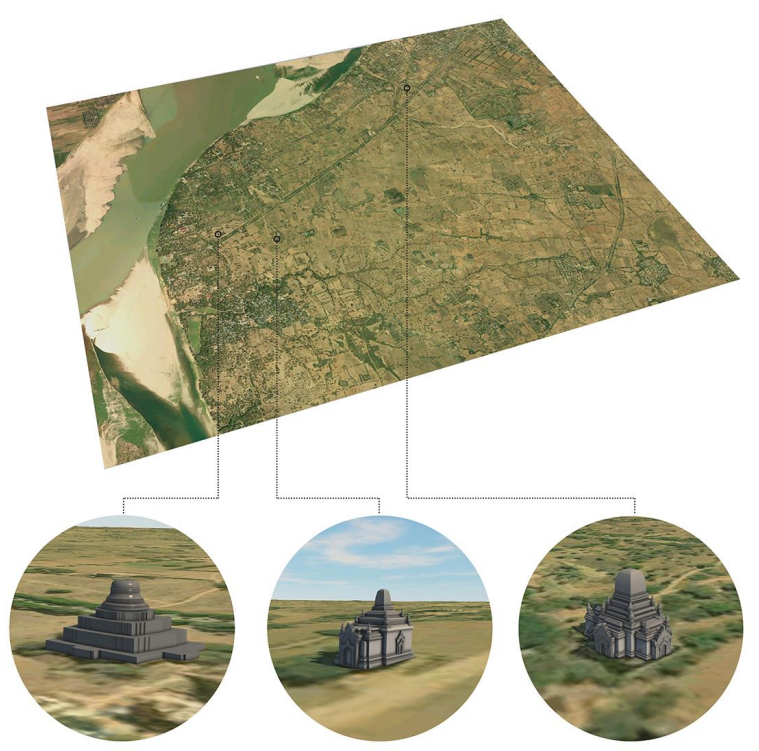

Figure 8. GIS of Old Bagan incorporating the model at LOD

(3) of the temples: Myin-pya-gu, Loka-hteik-pan, and Kubyauk-nge.

All the metadata collected will follow the existing standards. Since the publication of La conservation des peintures murals (The conservation of mural paintings) in 1977 (Mora et al., 1977), and Conservation of Wall Paintings by the Getty Conservation Institute in 1992 (Cather, 1992), organizations such as ICCROM (International Centre for the Study of the Preservation and Restoration of Cultural Property), ICOM-CC (International Council of Museums-Committee for Conservation) working group 'Mural, Stone and Rock Art Forum' or Historic England have developed various standards, working documents, and publications to help improve the terminology of wall paintings.

Current workflows related to the documentation of wall painting, especially in the area of Bagan, are not digitized or use a text-based format. The main objective of this work is to gather all the existing information in a single model and emphasize the importance to establish relationships among them at all three different scales. To that end, we propose the use of the standard $\mathrm{CSV}$ format as a way of sharing information and metadata between the three scales. For example, the multi-scale documentation information could include:

1. Context:

- Accession number

- Name

- Coordinates

- Building type

- Time of construction

- Condition

\section{Wall paintings:}

- Location

- Art historical style/iconography

- General painting technology (secco / fresco, earthenbased / lime-based, pigment type)

- Current condition (intact / stable but with problems / ongoing deterioration / collapsed) 
- Existing investigation type (invasive sampling, noninvasive sampling, visual assessment, etc.)

- Conservation state (original / previous conservation / ongoing conservation)

- Deterioration or damage related to context (geological / hydrological / environmental issues, earthquakes / fires etc.)

3. Documentation history:

- Copyright (Pierre Pichard, CIMS, etc.)

- Date and scope

- Method/technique

- Monitoring locations and focus

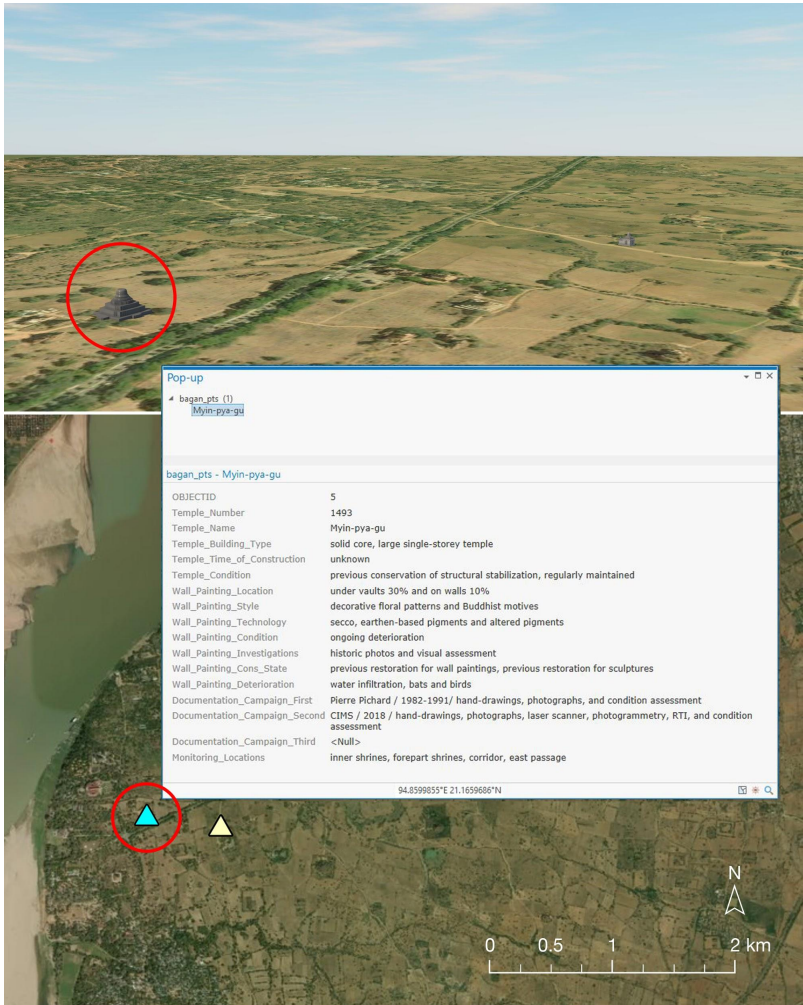

Figure 9. Temple and Wall painting metadata.

\section{CONCLUSIONS}

This paper explores the possibilities to generate a comprehensive methodology to document and manage wall paintings that belong to a large group of heritage assets, considering its four-dimensionality at multiple scales. To that end, it is proposed that the use of different digital technologies and applications that are integrated into a common database with the objective to gather and sort data from time to time according to specific requirements. The multi-scale approach has been used before in heritage conservation, but it faced two challenges: the accuracy of the metric data, and the introduction of coherent non-metric data at all scales. This was addressed in the past by combining BIM and GIS, allowing the fusion of accurate models and sites with cartographic tools (Remondino et al., 2016).

In our proposal, BIM is understood as the joint between different scales, creating a relevance from the fine detail of the decorated surface to the large-scaled territory. This paper addresses interoperability at a basic level between three different scales: (1) surface and building, (2) building and territory, and (3) surface and territory. The objective is to create data exchange among different platforms and users, generating a collaborative instrument that evolves over time with the participation of different specialists.

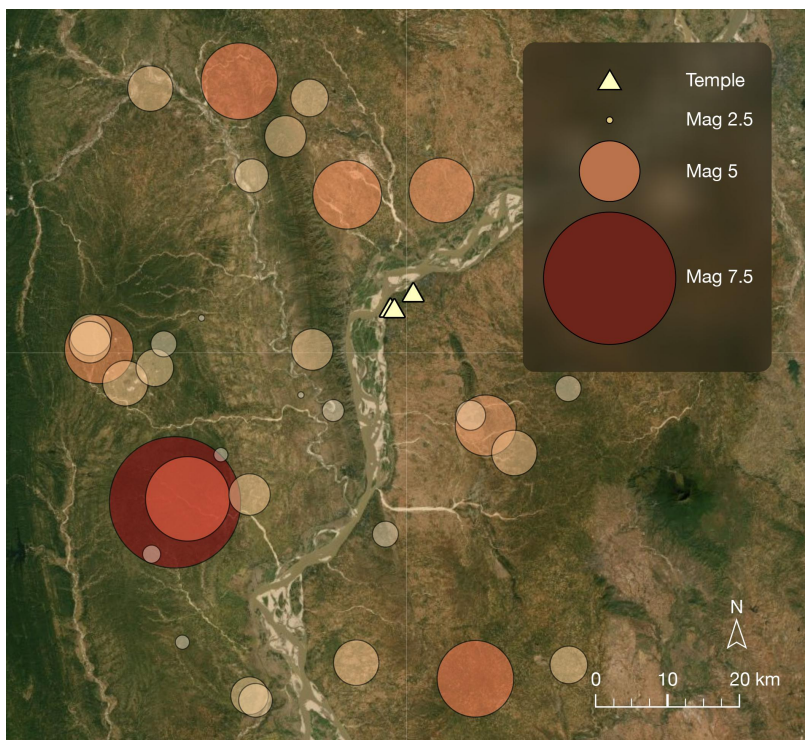

Figure 10. Earthquake position and impact in relation to the documented temples.

\section{ACKNOWLEDGEMENTS}

The authors wish to thank Myanmar's Department of Archaeology, National Museum and Library (DoA) for the opportunity to collaborate in the documentation of this temple. This work was supported by the NSERC Create Heritage Engineering grant at Carleton University.

\section{REFERENCES}

Abate, D., Hermon, S. and Eliades, I., 2016. "Virtual and Physical Recomposition of Fragmented Ecclesiastical Frescoes Using a Photogrammetric Approach." In International Archives of the Photogrammetry, Remote Sensing \& Spatial Information Sciences - ISPRS Archives, 41:153-60.

doi:10.5194/isprsarchives-XLI-B5-153-2016.

Scala, B., Adami, A. and Spezzoni, A., 2017. "Modelling and accuracy in a BIM environment for planned conservation: The apartment of Troia of Giulio Romano." In The International Archives of the Photogrammetry, Remote Sensing and Spatial Information Sciences, Volume XLII-2/W3, 2017 3D Virtual Reconstruction and Visualization of Complex Architectures: 1723.

Agnew N., Demas M. ed., 2013. Visitor Management and Carrying Capacity at World Heritage Sites in China. Extended Abstracts of the International Colloquium, The Getty Conservation Institute, Los Angeles.

Andreoli, M. 2014. "Mosaics of Frescoes: Digital Photogrammetry, Raster Representation, Pigment Analysis and Metrology of a Flavian Wall Painting on the Caelian Hill (Rome)." In Cambridge Archaeological Journal 24 (2). Cambridge University Press:233-48. doi:10.1017/S0959774314000420. 
Andrews, D. D., Bedford, J., Papworth, H., \& English Heritage, 2009. Measured and drawn: Techniques and practice for the metric survey of historic buildings (2nd ed.). Swindon: English Heritage.

Barton, C., Cox, A., Delgadillo Cruz, S., Hansen, J. 2017. "Cultural-heritage Inventory Implementations The Versatility of the Arches System." In APT Bulletin: The Journal of Preservation Technology, 48(4):19-28.

Cather, S. ed., 1992. The Conservation of Wall Paintings: Proceedings of a Symposium Organized by the Courtauld Institute of Art and the Getty Conservation Institute, London, July 13-16, 1987. Getty Publications.

Cather, S., Schmid, W., 2000. "Costing Graphic Documentation: How Much Money and Whose Time?" In GraDoc: Graphic Documentation Systems in Mural Painting Conservation: Research Seminar, Rome 16-20 November 1999, edited by Werner Schmid, 16-19. Rome: ICCROM.

Cather S., 2010. "Choices and Judgment: The Professional Conservator at the Interface." In Conservation of Ancient Sites on the Silk Road, Proceedings of the Second International Conference on the Conservation of Grotto Sites, Mogao Grottoes, Dunhuang, People's Republic of China, June 28-July 3, 2004, The Getty Conservation Institute, Los Angeles, 2010:22-32

Cosentino, A., Stout, S. and Scandurra, C., 2015. "Innovative Imaging Techniques for Examination and Documentation of Mural Paintings and Historical Graffiti in the Catacombs of San Giovanni." In International Journal of Conservation Science 6(1):23-34.

Daniilia, S., Sotiropoulou, S., Bikiaris, D., Salpistis, C., Karagiannis, G., Chryssoulakis, Y., Price, B., and Carlson, J., 2000. "Panselinos' Byzantine Wall Paintings in the Protaton Church, Mount Athos, Greece: A Technical Examination." In Journal of Cultural Heritage 1(2):91-110.

https://doi.org/10.1016/S1296-2074(00)00164-3.

Demas, M., Agnew, N. ed,. 2012. Valley of the Queens Assessment Report Volume 1. The Getty Conservation Institute, Los Angeles.

Fai, S., Graham, K., Duckworth, T., Wood, N. and Attar, R., 2011. "Building information modelling and heritage documentation." In Proceedings of the 23rd International Symposium, International Scientific Committee for Documentation of Cultural Heritage (CIPA), Prague, Czech Republic:12-16.

Fontana, R., Gambino, M.C., Greco, M., Marras, L., Materazzi, M., Pampaloni, E., Pezzati, L., and Poggi, P., 2003. "Integrating 2D and 3D data for diagnostics of panel paintings." In Optical Metrology for Arts and Multimedia 5146:88-99.. International Society for Optics and Photonics.

https://doi-org.proxy.library.carleton.ca/10.1117/12.501247.

Madden, M. ed., 2009. Manual of Geographic Information Systems. Bethesda, MD: American

Society for Photogrammetry and Remote Sensing.

Martin de Fonjaudran, C., Tringham, S., Bogin, S., Menon, S., and Jasol, K., 2011. "Cultural identity, conservation approaches, and dissemination: conserving the wall paintings of Nagaur Fort,
Rajasthan, India.” In ICOM-CC 16th Triennial Conference 2011 Proceedings Lisbon: Almada:1-8.

Mezzino, D., Esponda, M., Chan, L., and Santana, M., 2017. Myanmar, Architectural Documentation of Historic Temples. Unpublished.

Mora, P., Mora, L., and Philippot, P., 1977. La Conservation des Peintures Murales. International Centre for the Study of the Preservation and Restoration of Cultural Property.

Nieto, J. E., Moyano, J.J., Delgado, F.R., and García, D.A.. 2016. "Management of Built Heritage via HBIM Project: A Case of Study of Flooring and Tiling." In Virtual Archaeology Review 7(14):1-12. doi:10.4995/var.2016.4349.

Nocerino, E., Rieke-Zapp, D. H., Trinkl, E., Rosenbauer, R., Farella, E. M., Morabito, D., and Remondino, F., 2018. "Mapping VIS and UVL Imagery on 3D Geometry for NonInvasive, Non-contact Analysis of a Vase." In International Archives of the Photogrammetry, Remote Sensing \& Spatial Information Sciences, 42(2):773-80. https://doi.org/10.5194/isprs-archives-XLII-2-773-2018, 2018.

Pamart, A., Guillon, O., Faraci, S., Gattet, E., Genevois, M., Vallet, J.M. and De Luca, L., 2017. "Multispectral photogrammetric data acquisition and processing for wall paintings studies." In ISPRS-International Archives of the Photogrammetry, Remote Sensing and Spatial Information Sciences 42:559-566. Copernicus GmbH.

https://doi.org/10.5194/isprs-archives-XLII-2-W3-559-2017.

Pamart, A., Ponchio, F., Abergel, V., Alaoui M'Darhri, A., Corsini, M., Dellepiane, M., Morlet, F., Scopigno, R. and De Luca, L., 2019. "A Complete Framework Operating SpatiallyOriented RTI in a 3D/2D Cultural Heritage Documentation and Analysis Tool." In ISPRS-International Archives of the Photogrammetry, Remote Sensing and Spatial Information Sciences 422:573-580.

https://doi.org/10.5194/isprs-archives-XLII-2-W9-573-2019, 2019.

Pichard, P., 1992. Inventory of monuments at Pagan. Paris: UNESCO.

Rahrig, M., Drewello, R., and Lazzeri, A., 2018. "Optotechnical Monitoring - A Standardized Methodology to Assess The Treatment of Historical Stone Surfaces." In International Archives of the Photogrammetry, Remote Sensing \& Spatial Information Sciences, 42(2):945-952.

https://doi.org/10.5194/isprs-archives-XLII-2-945-2018, 2018.

Remondino, F., Rizzi, A., Barazzetti, L., Scaioni, M., Fassi, F., Brumana, R., and Pelagotti, A., 2011. "Review of Geometric and Radiometric Analyses of Paintings." In The Photogrammetric Record, 26(136):439-461.

https://doi.org/10.1111/j.1477-9730.2011.00664.x

Remondino, F., and Stylianidis, E., 2016. $3 D$ recording, documentation and management of cultural heritage (Vol.2). Caithness, Scotland, UK: Whittles Publishing.

Schroer, C., Mudge, M., Leisch, E., and Doerr, M., 2017. “A Context Metadata Collection and Management Tool for Computational Photography Projects." In Archiving Conference 2017(1):99-104. Society for Imaging Science and Technology. 
The International Archives of the Photogrammetry, Remote Sensing and Spatial Information Sciences, Volume XLII-2/W15, 2019 27th CIPA International Symposium "Documenting the past for a better future", 1-5 September 2019, Ávila, Spain

Theban Mapping Project, 2004. The Valley of the Kings Site Management Masterplan, Theban Mapping Project, Cairo, Egypt.

http://thebanmappingproject.com/about/masterplan.html.

Wong L., Graves K., and Wang X., Assessment of Cave Condition and Visitation Potential, Final report undertaken as part of the Visitor Carrying Capacity Study at the Mogao Grottoes, China, June 2012. 